\title{
Implant Surgery Using Bio-compatible Guides
}

\author{
SERBAN TALPOS ${ }^{1}$, TAREQ HAJ AJ ${ }^{2 *}$, COSTIN TIMOFTE ${ }^{3}$, MIRCEA RIVIS ${ }^{1}$, FELICIA STREIAN ${ }^{1}$, MALINA POPA ${ }^{2}$, COSMIN SINESCU ${ }^{2}$, \\ MEDA LAVINIA NEGRUTIU ${ }^{2}$, ADRIAN STAN², CRISTIAN ZAHARIA², CAMELIA SZUHANEK², EMILIA IANES ${ }^{1}$, MARIUS PRICOP1 \\ 'Victor Babes University of Medicine and Pharmacy, Faculty of Dentistry, Department II, 2 Eftimie Murgu Sq., 300041, Timisoara, \\ Romania \\ ${ }^{2}$ Victor Babes University of Medicine and Pharmacy, Faculty of Dentistry, Department I, 2 Eftimie Murgu Sq. , 300041, Timisoara, \\ Romania \\ Talpos Dental Team, 19Martir Ion Miron, 300254, Timisoara Romania
}

\begin{abstract}
Implants and biomaterials used in hard and soft oral tissue augmentation are very complex, but predictable to use nowadays, as the technological advances haven't skipped this field of medicine. Cases that were impossible to treat with implant retained fixed prosthesis some years ago, have become the daily practice of oral surgeons and dentists around the world. The new user-friendly products, together with simplified protocols, increased the practitioners' predictability and success rate, thus the biomaterial industry took a huge leap forward. As the biomaterial industry keeps developing continuously, making better and safer products, the surgical and prosthetic protocols evolve and change as well. On this matter, the implant placement has become safer, using digital surgical guides. Guided implant placement doesn't just allow the practitioner place the implant in the patient's bone, but, moreover, it helps him place it in the correct, 3D, prosthetic position. And, thus, guiding the future bone augmentation and regeneration as well, accordingly. So, the implant placement has shifted from bone-orientated to prosthetic-orientated, offering at the same time a better primary stability for the implants, due to the prior planning. The present clinical study aims to analyze the outcome of the digital guided protocol. Unlike the free-handed surgery, the digital guided surgery allows dentists and oral surgeons to place implants according to the future prosthetic position of the crowns, even in conditions of alveolar ridges with bone resorption. Moreover, it makes possible the "one day implant" concept, the dental technician being able to create the provisional crown/s in advance, knowing precisely the future position of the implant placement. So, at the time of the surgery, the provisional crown is also put in place, guiding the soft and hard tissue healing and also giving the patient a greater satisfaction.
\end{abstract}

Keywords: Implants, Guided surgery, Bone augmentation,Osseointegration, Dental SG

The implant based therapy is very complex and challenging, but predictable in the same time. One of the main issues regarding the $21^{\text {st }}$ century implantology is, besides the implant placement itself, the augmentation of hard and soft tissues in order to achieve maximum functional and aesthetic results for the patient.

Many cases need some sort of augmentation for a variety of reasons. Some patients need bone augmentation due to the high resorption of the alveolar bone, while other need connective tissue grafts in order to recreate the natural appearance of the crown. And, of course, some cases require both type of augmentation - hard and soft tissue.

When dealing with bone augmentation, one of the biggest debates in the literature is the nature of the graft. Some authors recommend xenografts or alloplasts, while others opt for allografts or autografts, or even the mixing of 2 or more types [1]. Xenografts have the advantage of low to no resorption on a long term, but may have some problems when dealing with big bone defects, regarding the vascularization and bone formation [2],Allografts and autografts have the advantage of being more stable when dealing with large bone defects and also they ease the blood vessel formation [3-6]. All types of grafts have advantages and disadvantages; Some related to the surgical protocol, while others to the cellular proprieties as bone formation and induction. As J ie Liu and David G Kerns say in the 2014 bone augmentation techniques review, 'Autogenous bone harvested from the patient forms new bone by osteogenesis, osteoinduction, and osteoconduction. Allografts harvested from cadavers have osteoconductive and possibly osteoinductive properties, but they are not osteogenic. Xenografts/ alloplasts are typically only osteoconductive [7].

The main goal of implant placement and bone grafting procedures is to obtain the the neo-formation of blood vessels, necessary for bone growth and development. This biological phenomenon, taking place at microscopic level, will eventually lead to a healthy bone, surrounding a biointegrated dental implant, which translates into a clinical long-term success[ 8-10].

During traditional, free-hand surgery protocol, the bone augmentation can take place prior to the implant placement, when bone defects are very large, or at the same time. One of the advantages of guided implant placement is that the oral surgeon can do the augmentation simultaneously, even in cases with some level of bone defects. This is due to the mechanical guidance and support given by the surgical guide during operation, which helps the oral surgeon to maintain a stable position of the drill and prevents potential sideswiping, which can often occur in such cases [11]. This represents a major advantage for the patient, as no secondary surgery is needed. Another main advantage is the proper prosthetic planning for the final implant retained restoration. As important as the surgical part is, the final goal of an implant therapy is the function of the future crowns in the oral cavity. The correct 3D placement, from the prosthetic point of view, of dental implants, is absolutely necessary in order to obtain a complete biological integration. Using CADCAM implant guides, the oral surgeon obtains exactly this: implant placement that follows not only the thickest part of the alveolar ridge - as many times happens during free-

\footnotetext{
*email: tareq_hajaj@yahoo.com; Phone: 0040766320438
} 
hand surgery - but the correct prosthetic position. So the bone augmentation that follows is guided as well, on prosthetic consideretions.[12, 13].

But probably the biggest advantage of the CAD-CAM guided implant placement and bone grafting is the, so called, One day implant concept. This allows the oral surgeon to provide the patient with a provisional prosthesis, or, sometimes, even the final one, at the same time with the surgery. This is possible due to the precise and planned surgical outcome which gives the dental technician the opportunity to create in advance the prosthetic piece. This immediate provisional is benefic for the patient, not only for aesthetic reasons, but also for the guided regeneration and healing of the soft tissues. Having a good and fast soft tissue healing will create the premises for the bone integration of the dental implants.

\section{Experimental part}

\section{Materials and methods}

A case was selected for the guided implant surgery. The patient - female, 26, had the upper right second premolar and first molar $(15,16)$ missing and the first premolar (14) with an indication for extraction.

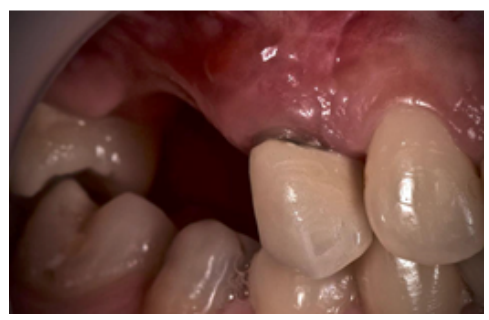

Fig. 1.Initial situation

At the first appointment, an intra-oral scan was performed with TRIOS 3Shape. Afterwards, the patientwas sent for a cbctanalysis to collect the 3D data of the maxillary, necessary for the future digital planning.

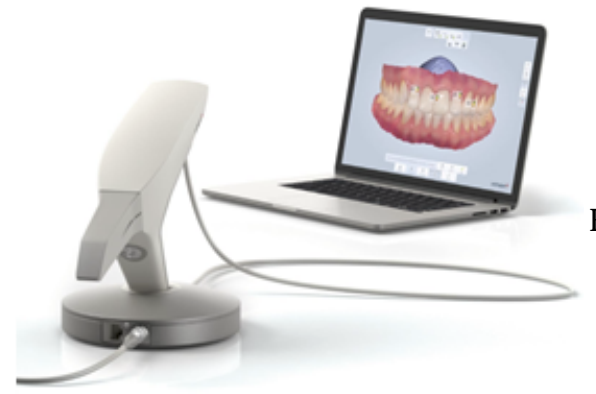

Fig. 2.TRIOS 3Shape

After both paraclinical investigations were achieved, the digital planning of the implants placement was done, using Implant design software (3Shape), to follow the future position of the prosthetic restoration. Once the correct 3D position was determined, the guide was digitally designed accordingly.

The design of the guide was then sent to the dental laboratory. The dental technician 3D printed the guide from a biocompatible resin - Dental SG. The 3D printer model used was a Form 2. Afterwards, the dental technician created a PMMA provisional prosthetic restoration using a CAD-CAM device, based on the initial digital planning done in the dental office. The abutments used were hybrid -

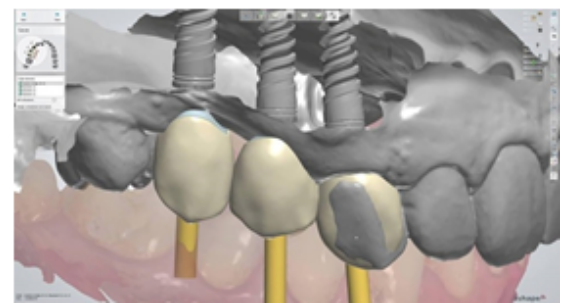

Fig. 3. Digital planning of the implant placement
Fig. 5.PMMA provisional restoration

By the next appointment, the Dental SGguide and the provisional restoration were ready to use and the patient was prepared for the surgical intervention.

In local anesthesia, 14 was extracted and a full thickness buccal flap was raised, in order to gain full access to the future implant site. Afterwards, the surgical guide was set in place and the drilling procedure started according to the conventional protocol, using the Alpha Bio guided surgery implant kit.

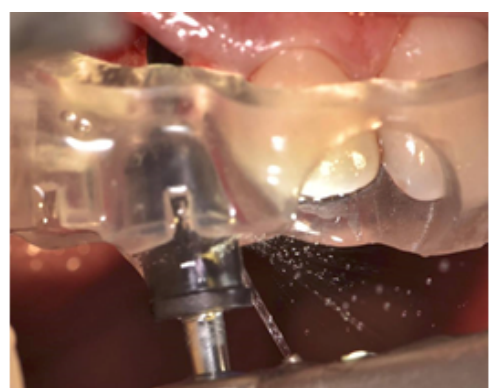

Fig. 6.Drilling procedure using the surgical guide

Once the implant sites were ready, 3 Alpha-Bio Neo implants were inserted using a torque wrench. The placement of the 3 implants was done easily and very predictable, the position being accurately respected due to the surgical guide. So not only the buccal-lingual position was pre-determined, but also the depth of the placement.

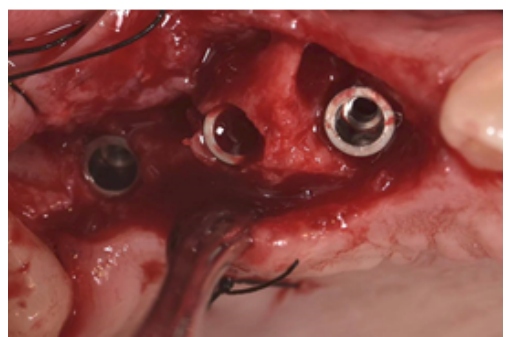

Fig. 7. Implants inserted in the maxillary bone

After the 3 implants were inserted $-14,15,16$ - the abutments were set in place and the hard and soft tissue augmentation followed. In the first part, the bone augmentation was performed using xeno (Bio-Oss) and autograft bone granules in a 50-50\% ratio. Subsequently, a resorbable collagen membrane (Bioguide) was used to cover and protect the graft, in order to obtain a healthy, good quality bone

The next step was the soft tissue augmentation, for which a connective tissue graft was harvested from the hard palate of the patient. This was inserted between the periosteum and the mucosa of the buccal flap and stabilized 


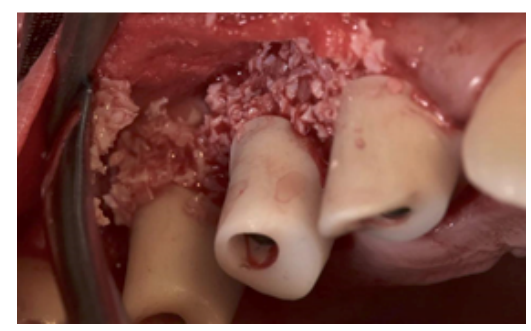

Fig. 8. Bone grafting procedure

with sutures. Once the grafting was completed, the flap was relaxed and closed and the provisional restoration was cemented on the abutments using a temporary cement. The occlusal check-up was done, making sure that the provisional was not functional. The only two purposes for the provisional restoration, at this stage, were 1- aesthetics and 2- conformation of the soft tissues around the abutments.

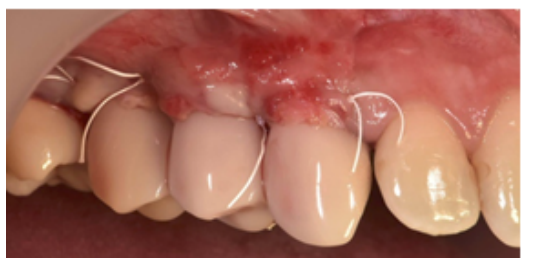

Fig. 9. Provisional restoration immediately post-op

The patient was keptunder supervision for the following period, with regular checkups starting the next day and continuing once a week for 2 months. The sutures were removed after 7 days.

The implants had a very good primary stability from the beginning, due to the digital guided surgical protocol, thus ensuring a predictable provisional prosthetic restoration. This led to a stable growth and development of the surrounding soft tissues.

The healing process has been going on without any problems and the implants site did not show any visible sings of infection and/or inflamation after one week from surgery.

The soft tissues around the abutments were in a very good condition with a healthy-looking color and texture. Furthermore, at 8 weeks post-op, in the spaces between the abutments, the papillae were starting to grow, giving the prosthetic restoration a natural, healthy look.

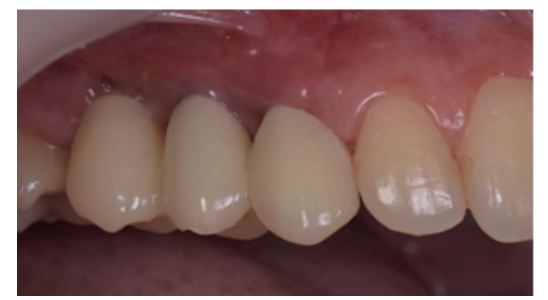

Fig. 10. Clinical aspect with the provisional in place 8 weeks post-op

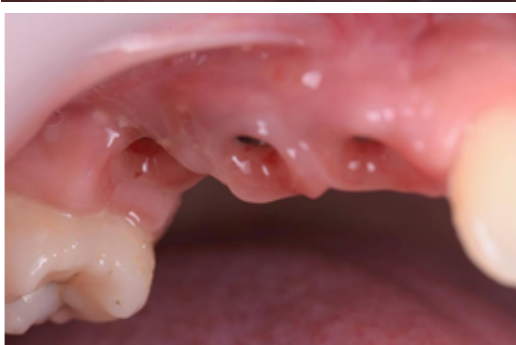

Fig. 11. Clinical aspect without the provisional 8 weeks post-op

The clinical aspect at the 2 months check-up after the surgery confirmed that the intervention was a success and that the guided protocol and direct provisional have led to the desired outcome.

The outcome of any implant treatment depends on many factors, such as surgical protocol, the general condition of the patient, the oral status, provisional and final prosthetic restoration, type of implant and, of course, oral hygiene [14]. All of them can influence, more or less, the the long term success of the implant therapy
Straight from the beginning of the surgical procedure, the advantages of guided implantology are obvious. From the planned position of the implant, to the stability and accuracy of the drills throughout the surgical process and the possibility of fixing the PMMA provisional in the same session, all contribute to a more predictable and userfriendly working protocol.

As a comparison with the free-handed surgery, the guided implant placement offers the clinician more safety. As for the patient, it offers more comfort and better soft tissue healing, due to the immediate loading of the implants.

\section{Conclusions}

The design of the flap and the position of the drilling are both planned precisely from before. All the decision making happens, precisely, previous to the surgery, so the chances of unexpected errors are much lower.

The accuracy and the stability of the drilling throughout the process are highly predictable and, so, the risk of any sidesliping is reduced. Thus, accidents are easily prevented and the practitioner has a better control during the surgery

The possibility of designing and manufacturing the PMMA provisional prior to the intervention, allows the practitioner to place the fixed partial denture in the same session[15-17]. This offers numerous advantages for both, the clinician and the patient [18]. For the clinician it offers the chance to check the correctness of the implant placement. Moreover, it helps guide the healing of the soft tissues, increasing the chances of an aesthetic outcome. For the patient, it means a lotmore comfortand confidence as the prosthesis is fixed immediately in place.

Overall, the guided implant placement makes the treatmentmore predictable, safer and user-friendly. Its only disadvantage, if there is one, is the learning curve, which, actually, accompanies any new procedure or protocol.

\section{References}

1. ANDREESCU, C. F., GHERGIC, D.L., BOTOACA, O., BARBU, H.M., CERNUSCA-MITARIU, I.S., PATROI, D.N., Mat. Plast., 54 ,no. 1, 2016, . 2017, p. 32

2.ANTONIO, B., NICOLONICOLIALDINI, MILENA FINI, ROBERTO GIARDINO, JOSE LUIS CALVOGUIRADO, AND UGO COVANI. Xenograft Versus Extraction Alone for Ridge Preservation After Tooth Removal: A Clinical and Histomorphometric Study. Journal of Periodontology, August 2008, Vol. 79, No. 8, Pages 1370-1377

3.SIMION, MASSIMO; JOVANOVIC, SASCHA A.; TRISI, PAOLO; SCARANO, ANTONIO; PIATTELLI, ADRIANO. Vertical Ridge Augmentation Around Dental Implants Using a Membrane Technique and Autogenous Bone or Allografts in Humans. International Journal of Periodontics \& Restorative Dentistry.Feb1998, Vol. 18 Issue 1, p8-23. 16p.

4.LUCA CORDARO, DAVID S AMADE, MASSIMO CORDARO. Clinical results of alveolar ridge augmentation with mandibular block bone grafts in partially edentulous patients prior to implant placement. Clinical Oral Implants Research J ournal, volume 13, Issue 1, February 2002 , pages 103-111

5.CHIAPASCO, MATTEO; CASENTINI, PAOLO; ZANIBONI, MARCO. Bone Augmentation Procedures in Implant Dentistry. International Journal of Oral \& Maxillofacial Implants. 2009 Supplement, Vol. 24, p237-259. 23p. 5 Charts.

6.GHIBAN, N., BORTUN, C. M., BORDEASU, I., GHIBAN, B., FAUR, N., CERNESCU, A., HANGANU, S.C., Mat. Plast.,47, no. 2, 2010, p. 240

7.JIE LIU, DAVID G KERNS. Mechanisms of Guided Bone Regeneration: A Review. Open Dent J. 2014; 8: 56-65

8.TORD BERGLUNDH, INGEMAR ABRAHAMSSON, NIKLAUS P. LANG, JAN LINDHE. De novo alveolar bone formation adjacent to endosseous implants. Clinical Oral Implants Research Journal, Volume 14, issue 3, May 2003, pages 251-262. 
9.T. ALBREKTSSON, C. J OHANSSON. Osteoinduction, osteoconduction and osseointegration. European Spine J ournal, October 2001, Volume 10, Supplement 2, pp S96-S101

10.CRETESCU, I., ROPCIUC, S., AHMADI, M., RADA, O.A., OSTAN, M., Rev. Chim. (Bucharest), 67, no. 4,2016, p. 796

11.SHETTY, MANO]; PRASAD D., KRISHNA; PATEL, AADIT B. Guided Implant Surgery. Guident.Feb.2015, Vol. 8 Issue 3, p16-18. 3p.

12.CHRISTOPHER B.MARCHACK DDS. CAD/CAM-guided implant surgery and fabrication of an immediately loaded prosthesis for a partially edentulous patient. The Journal of Prosthetic Dentistry, Volume 97, Issue 6, June 2007, Pages 389-394

13.PUIG, CARMEN POMARES. A retrospective study of edentulous patients rehabilitated according to the all-on-four or the all-on-six immediate function concept using flapless computer-guided implant surgery. European Journal of Oral Implantology. 2010, Vol. 3 Issue 2, p155-163. 9p. 14 Color Photographs, 3 Black and White Photographs.
14.CARLOS NELSON ELIAS - Factors Affecting the Success of Dental Implants. Implant Dentistry - A Rapidly Evolving Practice. 978-953-307658-4, 544 pagesAugust 29, 2011.

15.SZUHANEK, C., GRIGORE, A., FLESER, T. The applications of thermoplastic materials in the fabrication of orthodontic aligners, Mat. Plast., 52., no.3, 2015, p. 85

16.BUZATU, R., GOTIA, S.L., VALCEANU, S., SCROBOTA, I., ONISEI, D., SZUHANEK C.,The Dynamics of Salivary Parameters in Patients Undergoing OrthodonticTreatment, Rev. Chim.(Bucharest), 68, no. 3, 2017.

17.DAVID, O.T., SZUHANEK, C., TUCE R,.A., DAVID, A.P., LERETTER, M., Polylactic Acid 3D Printed Drill Guide for Dental Implants Using CBCT. Rev. Chim.(Bucharest),68, no.2, 2017, p. 341

18. SZUHANEK, C., GRIGORE, A., Determination of microelements from orthodontic implans by the flame atomic absorption spectroscopy method. Rev. Chim. (Bucharest), 66, no. 10, 2015, p. 1600

Manuscript received: 19.07 .2017 